\title{
How do fluid seepages impact the diagenetic sequence in the sedimentary column? A modelling approach
}

\author{
LUCIE PASTOR ${ }^{1}$, MARK ZINDORF ${ }^{1}$, JURJEN ROOZE ${ }^{2}$,
} CHRISTOF MEILE $^{2}$, CHRISTOPHE BRANDILY ${ }^{1}$ AND GWENAËL JOUET ${ }^{3}$

${ }^{1}$ Ifremer, centre de Brest, REM/EEP/LEP

${ }^{2}$ Department of Marine Sciences, University of Georgia

${ }^{3}$ Ifremer Brest

Presenting Author: lucie.pastor@ifremer.fr

Many studies try to quantify gas emissions from the seafloor to the water column and ultimately the atmosphere and their contributions to the global greenhouse gas budget. However, even before reaching the water column, the rising gas (mainly consisting of methane) can undergo oxidation that prevent it from escaping the seafloor. In this study, we applied a numerical model to simulate methane formation and/or upward migration in the sedimentary column, and its subsequent impact on early diagenetic processes with a focus on $\mathrm{C} / \mathrm{S} / \mathrm{Fe}$ budgets. Two locations in the Mozambique Channel were investigated. On the Mozambican continental slope, offshore the Zambezi River, the reconstruction of methane migration during the past $27 \mathrm{kyr}$ was closely related to fluctuations in organic matter deposition. Substantial variation in the intensity and depth of sulfate reduction, in relation with organic matter mineralization and anaerobic oxidation of methane, revealed its impact on authigenic minerals precipitation (i.e. pyrite). On the Malagasy continental slope, offshore the Betsiboka River, two sediment cores, located $1 \mathrm{~km}$ apart and receiving sediment input of similar composition indicate different forcing, with only one of them being impacted by gas rising from a greater depth. Using reactive transport modeling, we distinguish these two settings and assess the impact of fluid and gas migration on $\mathrm{C} / \mathrm{S} / \mathrm{Fe}$ cycling through oxidation-reduction reactions and authigenic minerals precipitation.

This research was co-funded by TOTAL and IFREMER as part of the PAMELA scientific project. 